Open Access

\title{
Prevalence and factors associated with stunting and thinness among adolescent students in Northern Ethiopia: a comparison to World Health Organization standards
}

Yohannes Adama Melaku ${ }^{1,3^{*}}$, Gordon Alexander Zello², Tiffany K. Gill ${ }^{3}$, Robert J. Adams ${ }^{3}$ and Zumin Shi ${ }^{3}$

\begin{abstract}
Background: Adolescence is last chance for curbing the consequences of malnutrition and breaking the intergenerational cycle of malnutrition and poor health. This study aimed to assess the prevalence and the factors associated with stunting and thinness among in-school adolescents in northern Ethiopia using the 2006 World Health Organization (WHO) standards.

Methods: In-school adolescents ( $n=348,10-19$ years old) were randomly selected to participate in this cross-sectional study. Anthropometric measurements were carried out to determine the proportion of adolescents who were stunted (height-for-age $<-2$ Standard Deviation (SD)) and thin (body-mass-index-for-age $<-2$ SD). T-test was employed to evaluate mean weight and height differences between groups. Pearson chi-square, chi-square trend and Fisher's exact tests were used to explore the crude association of categorical outcome variables and associated factors. Crude and adjusted associations between the outcome variables (stunting and thinness) and independent variables (socio-demographic, eating behavior and sanitation) were also determined using logistic regression. Stata version 11.1 was used to analyze the data.

Results: The height of the adolescents was $147.6 \pm 11.2 \mathrm{~cm}$ (mean \pm SD) and weight was37.2 $\pm 9.5 \mathrm{~kg}$. The mean Z-scores of height-for-age and body-mass-index (BMI)-for-age of adolescents were -1.49 and -1.29 , respectively. The prevalence of stunting and thinness among adolescents was $28.5 \%$ (boys $=37.7 \%$; girls $=21.2 \%$; $P=0.001$ ) and $26.1 \%$ (boys $=32.4$; girls $=21.6 \% ; p=0.017$ ), respectively. Adolescents in 13-15 year old age group (Adjusted Odds ratio $(A O R)=2.23 ; 95 \% \mathrm{Cl}: 1.22,4.08)$, boys $(A O R=2.53 ; 95 \% \mathrm{Cl}: 1.52,4.21)$ and rural residents $(\mathrm{AOR}=2.15$; $95 \% \mathrm{Cl}: 1.20,3.86)$ had significantly higher odds of being stunted compared to their counterparts. Furthermore, boys had higher (AOR $=1.97 ; 95 \% \mathrm{Cl}: 1.19,3.25)$ odds of being thin compared to girls. Compared to those 10 to 12 years of age, adolescents in 16 to 19 years of age were $53 \%(A O R=0.47 ; 95 \% \mathrm{Cl}: 0.23,0.95)$ less likely to be thin.
\end{abstract}

Conclusions: Undernutrition is widely prevalent among adolescents in northern Ethiopia. Sex, age and area of residence significantly associated with adolescent undernutrition. The study underlines the need for nutrition interventions targeting rural and boy adolescents.

Keywords: Adolescent, Student, Ethiopia, Undernutrition, WHO standards

\footnotetext{
*Correspondence: adamayohannes@gmail.com

${ }^{1}$ School of Public Health, College of Health Sciences, Mekelle University,

Mekelle, Ethiopia

${ }^{3}$ School of Medicine, The University of Adelaide, Adelaide, South Australia,

Australia

Full list of author information is available at the end of the article
}

\section{Biomed Central}

(c) 2015 Melaku et al. Open Access This article is distributed under the terms of the Creative Commons Attribution 4.0 International License (http://creativecommons.org/licenses/by/4.0/), which permits unrestricted use, distribution, and reproduction in any medium, provided you give appropriate credit to the original author(s) and the source, provide a link to the Creative Commons license, and indicate if changes were made. The Creative Commons Public Domain Dedication waiver (http://creativecommons.org/publicdomain/zero/1.0/) applies to the data made available in this article, unless otherwise stated. 


\section{Background}

According to the World Health Organization (WHO) adolescence is defined as10-19 years of age [1]. Adolescents represent approximately $20 \%$ of the world's population and most ( $84 \%)$ are living in developing or emerging countries [2]. In Ethiopia, 20-26\% of the population was represented by adolescents [3]. Adolescence is a period characterized by important biological, physical, psychological and social changes [4] and an active growth phase [5]. Throughout this period, risk of nutrition inadequacies and other health issues are of concern due to rapid growth in stature, muscle mass and fat mass. During the peak of the adolescent growth spurt, some dietary requirements are also as high as or higher than in other age groups [6]. Adequate nutrition and health are essential as adolescents gain up to $50 \%$ of their adult weight, more than $20 \%$ of their adult height, and $50 \%$ of their adult skeletal mass during these years [7].

Despite the economic growth observed in developing countries, malnutrition and particularly undernutrition is still highly prevalent [8-12] though a growing prevalence of obesity is also being observed in some of these countries $[8,13]$. Ethiopia is not an exception. A study in northern Ethiopia reported high levels of stunting (26.5\%) and thinness (58.3\%) [12]. On the other hand, increased prevalence $(8.5 \%)$ of overweight/obesity was reported among adolescents in a city (Addis Ababa) [14]. This double-burden of malnutrition in children and adolescents adversely affects their intellectual development [15-19], school attendance [20], growth [19], health [21], academic performance and social skills $[15,17,19]$. For instance, a longitudinal study in southwest Ethiopia demonstrated the positive relationship between adolescent food insecurity and absenteeism and low success in schooling [22].

Poor nutrition status among adolescents is also an important determinant of poor health outcomes. Undernutrition has far reaching consequences, especially in girls. If their nutritional needs are not met, they have high risk of mortality as a result of pregnancy and childbirth and they are more likely to give birth to low birth weight infants [23-25]. Furthermore, in all adolescents, short stature resulting from chronic undernutrition is associated with reduced lean body mass and deficiencies in muscular strength and working capacity [26]. Thus, one approach to break the intergenerational cycle of malnutrition and poor health is to improve the nutrition of adolescents; otherwise, the vicious cycle will continue.

In Ethiopia, although childhood stunting is highly prevalent in general and in the region (Tigray) where this study was conducted in particular [10], data on adolescents are scarce. The few existing studies have reported varying levels of undernutrition among adolescents between 2009 and 2014. A national level survey on adolescent girls reported that $23 \%$ and $14 \%$ of adolescent girls were stunted and thin (as defined by WHO 2006 standard; Z-score $<-2$ ), respectively [10]. In Addis Ababa, the capital of Ethiopia, $7.2 \%$ and $6.2 \%$ of adolescents were found to be stunted and thin, respectively [14]. A study conducted among adolescent girls in rural communities of northern Ethiopia showed that the prevalence of stunting and thinness were $26.5 \%$ and $58.3 \%$, respectively [12]. Another study conducted in Ambo town showed that underweight was prevalent in boys than girls $(29.8 \%$ versus $24.6 \%$ ) with total prevalence of $27.5 \%$ [27].

To assess the nutrition status of adolescents, the WHO currently recommends using BMI-for-age and height-for-age $[28,29]$. The WHO growth standard for adolescents also uses thinness (low body-mass-index (BMI)-for-age (BAZ)) and stunting (low height-for-age (HAZ)) $[28,29]$. The main difference between these two indicators is that the former is a result of mainly acute (shortterm) nutrient deficiency (specifically macronutrients) whereas the later shows chronic (long-term) deficiency. Previous studies have used these standards to evaluate the nutrition status of adolescents and to compare prevalence of thinness and stunting in different settings [30-33].

Investigating growth, health and nutrition status during the adolescence stage of development, in addition to infancy and childhood is important. However, there are few studies that investigate stunting and thinness during adolescence in Ethiopia [12, 14, 34, 35] and there is only one study that has been conducted in northern Ethiopia with a focus on adolescent girls [12].

The main aim of this study was, therefore, to assess the prevalence and the factors associated with stunting and thinness among in-school adolescents (both boys and girls) in northern Ethiopia using the WHO standards [36]. Data obtained from this study are relevant to both governmental and non-governmental organizations interested in improving the health and nutrition of an important and often neglected segment of the population in developing and emerging countries.

\section{Methods}

\section{Study design, setting, sample size determination and sampling technique}

The study design was a school-based, cross-sectional study measuring the prevalence and factors associated with stunting and thinness among adolescents in a town in northern Ethiopia. The study was carried out from February to March, 2014.

The sample size was determined using a single population proportion formula, with the following assumptions: Maximum allowable error was set at $4 \%$; the proportion of stunted Ethiopian adolescents at $16 \%$ [35]; Z statistic of 1.96; and estimated non-response rate of $10 \%$. A sample 
size of 356 was determined; however, 8 students ( 3 boys and 5girls) declined to participate in the study, resulting in a final sample size of 348 .

The study was conducted in Wukro in the Tigray Region of northern Ethiopia. Wukro is located approximately 829 kilometer $(\mathrm{km})$ north of Addis Ababa and $45 \mathrm{~km}$ north of Mekelle (capital of the Tigray region). The total population is estimated to be more than 40,000. Six primary (Zikre-semaetat, Ksanet, Millennium, Kidus-Yossef, Bethntset and Selam) and two secondary (Megabit-30 and Wukro) schools were present in Wukro at the time of the study. In the academic year of 2013/2014, 10,073 adolescents (10-19 years of age) were attending school encompassing grades 5 to 12 . The $\mathrm{WHO}$ definition of the age range of adolescents (10-19 years) was used as the inclusion criteria for the study [1].

The number of study participants in both the primary and secondary schools was determined proportionally to population size. Three schools, namely Ksanet, Millennium and Selam, were selected using simple random sampling from the six primary schools in Wukro. Both of the secondary schools (i.e. Megabit 30 and Wukro) in Wukro were included. Primary and secondary schools were represented by 198 and 150 students, respectively.

Sampling frames (list of students between 10-19 years) were obtained from each school's administrators. Study participants from each school were then selected using a simple random sampling technique after allocating the number of study participants using proportion to population size. Room teachers (i.e. those responsible for supervision of students) assisted in identifying study participants. A schematic representation of participant selection is shown in Fig. 1.

\section{Measurements}

A pretested, self-administered, structured questionnaire (including both open-ended and closed-ended questions) was used in the study. The pretest was conducted among 38 students ( $10 \%$ of the sample) in schools that were found in the nearby town. The questionnaire was developed by reviewing previous literature [11, 12, 14, 27]. The English version of the structured questionnaire was translated into the local language, "Tigrigna". The questionnaire focused on socio-demographic characteristics (sex,

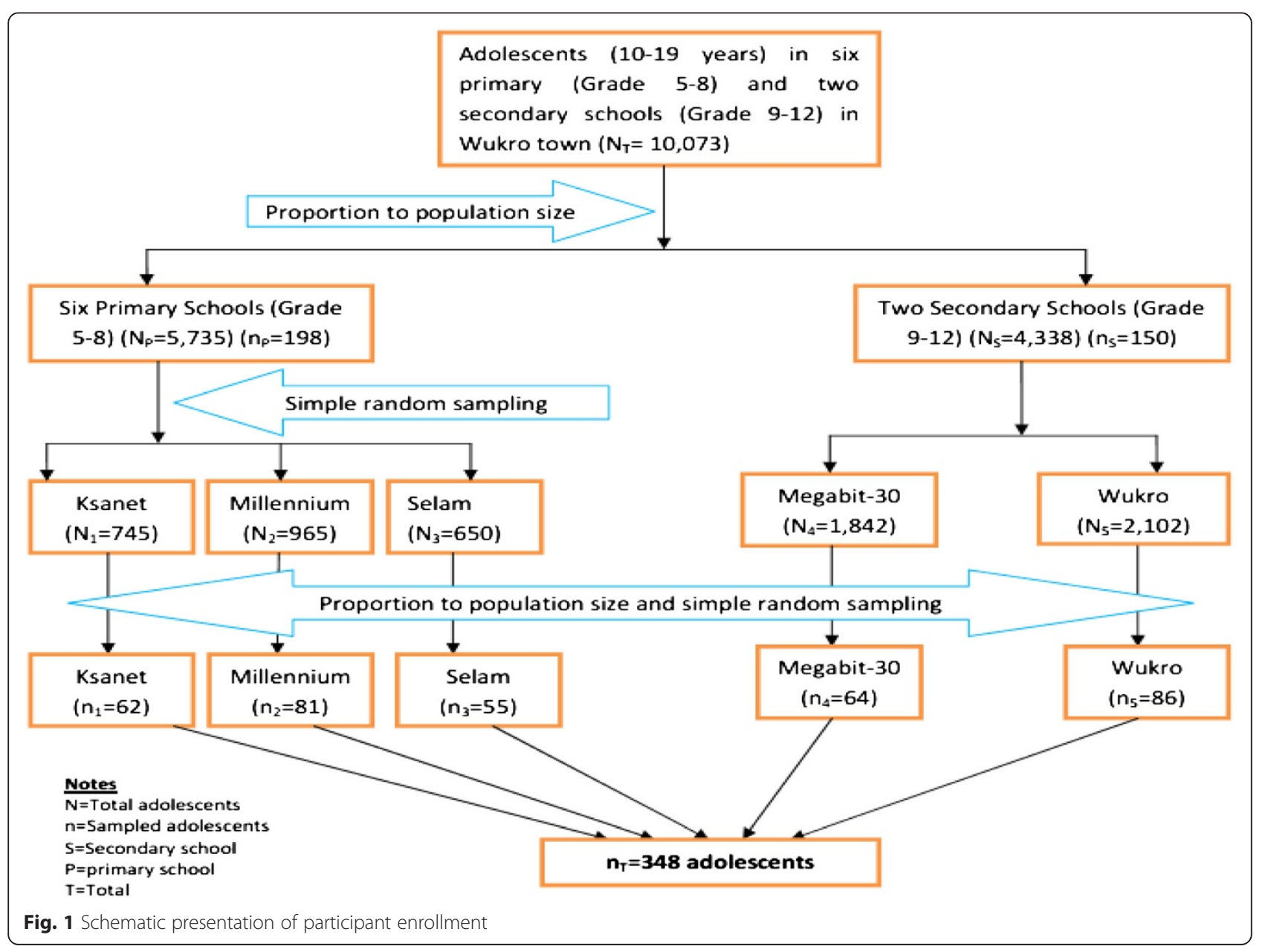


age, fathers' and mothers' education, usual place of residence, fathers' occupation, and number of family members), sanitation (functional latrine availability), eating behavior and anthropometric measurements. Each participant was asked about frequency of diet and type of foods eaten per day and week. Staple foods such as "Teff" (a cereal) with "Wot" (primarily prepared from legumes), wheat and others, vegetables, fruits and meat were included in the questionnaire. The presence of a functional latrine and water source for the household were also assessed. Furthermore, age differences of adolescents from their younger and older siblings were considered as a factor in the analysis in order to look the effect of age difference of siblings on adolescent nutrition status. Heights (to the nearest $0.1 \mathrm{~cm}$ ) and weights (to the nearest $0.1 \mathrm{~kg}$ ) of adolescents were measured using a stadiometer and balance beam scale (SECA, Hannover Germany), respectively. The height of each adolescent was measured without shoes. Weight was also measured without jackets or coats, shoes and additional clothing. Data collectors, who were university students, were trained on the contents of the questionnaire, procedures for data collection, data accuracy and completeness. Field work was conducted under close supervision of the principal investigators.

In each school, an official communication was used to identify a suitable time for data collection. Before completing the questionnaire, respondents were given a clear introduction explaining the purpose and objectives of the study. Data were collected during a single day in each participating school in the absence of class teachers, and efforts were made to ensure maximum comfort and privacy for the participants. Students were not allowed to discuss their questionnaire responses with each other, both for reasons of privacy and to avoid shared responses.

\section{Data management, quality control and analysis}

All possible actions to ensure quality of the data were performed before, during and after data collection. Training of data collectors and supervisors, pretesting of the questionnaire, and standardization of measuring scales of weight and height were undertaken. During data collection, consistency and completeness of questionnaires were checked by supervisors who had Bachelor degrees in health sciences. After data collection, unique codes (numbers) were provided for the questionnaire to facilitate cleaning of data whenever errors were detected. Data were entered into Statistical Package for Social Sciences (SPSS) version 20 (SPSS, IBM, New York) and WHO Anthro-Plus. They were then exported to Stata version 11.1 (Stata Corporation, College Station, TX, USA) for analysis.

Descriptive analysis such as mean, median, standard deviation (SD) and inter-quartile range (IQR) were used to describe characteristics of the study participants.
Anthropometric analysis determined the proportion of adolescents who were stunted $(\mathrm{HAZ}<=2 \mathrm{SD})$ and thin $(\mathrm{BAZ}<-2 \mathrm{SD})$ [29]. To evaluate mean weight and height differences between boys and girls, student $T$-test was used. In addition, $\chi^{2}, \chi^{2}$ trend and Fisher's exact tests were used to investigate the relationship of categorical outcome variables and associated factors.

The association between the outcome variables (i.e. stunting and thinness) and independent variables were first analyzed using bivariable logistic regression model. Covariates having $\mathrm{p}$-value $<0.25$ were retained and entered to the multivariable logistic regression analysis [37]. A p-value $<0.05$ was considered as a cut-off point for an independent variable to be significantly associated with the outcome. In the analyses, Hosmer-Lemeshow $\chi^{2}$ and Variance Inflation Factor (VIF) assessed the goodness-offit of the models and multi-co-linearity, respectively. All p-values of Hosmer-Lemeshow and VIF were greater than 0.05 and less than $10 \%$, respectively.

\section{Ethical considerations}

Ethical approval and an ethical clearance letter were obtained from the Institutional Review Board of Mekelle University. The education offices of Wukro, as well as school directors in Wukro, were informed through formal letters. The majority of students were less than 18 years and were unable to give consent. Considering this and since the questionnaire didn't contain sensitive issues, thorough discussions were undertaken with the school directors regarding the purpose and the contents of the data collection tool, and permission was obtained to conduct the study. Respondents were given assurances about the privacy and confidentiality of their responses. Informed oral consent was obtained from each participant to ensure their willingness to participate, and all were informed that they had the right to not participate or could withdraw from the study at any time.

\section{Results}

\section{Socio-demographic characteristics of adolescents in} relation to nutrition status

More than half of the study participants were girls and the median age of both sexes was 14 years. Two-thirds of the participants resided in urban areas. Nine out of ten of the participants identified as Orthodox Christians. The literacy rate of fathers and mothers were found to be $63.5 \%$ and $55.2 \%$, respectively (Table 1 ).

Stunting and thinness were significantly associated with sex. The overall prevalence of stunting among boys and girls were $37.7 \%$ (95 \% CI: $30.3 \%, 45.5 \%)$ and $21.2 \%(15.8 \%, 27.3 \%) \quad(p=0.001)$, respectively. Likewise, the prevalence of thinness among boys and girls were $32.4 \%$ (95 \% CI: $25.4 \%$, $40.2 \%$ ) and $21.6 \%$ (95\% CI: $15.8 \%, 27.3 \%)(P=0.017)$, respectively (Table 1$)$. 
Table 1 Socio-demographic characteristics of adolescents categorized by nutrition status (i.e. stunted and thin), northern Ethiopia, 2014

\begin{tabular}{|c|c|c|c|c|c|c|}
\hline Variables & Category & Total & Stunted $(<-2$ SD) $n(\%)$ & $P$-value* & Thin $(<-2$ SD) $n(\%)$ & $P$-value* \\
\hline \multirow[t]{2}{*}{ Sex } & Boys & $154(44.3)$ & $58(37.7)$ & 0.001 & $50(32.5)$ & 0.017 \\
\hline & Girls & $194(55.7)$ & $41(21.1)$ & & $41(21.1)$ & \\
\hline \multirow[t]{3}{*}{ Age in years } & $10-12$ & $120(34.5)$ & $25(20.8)$ & 0.002 & $35(29.2)$ & 0.036 \\
\hline & $13-15$ & $135(38.8)$ & $53(39.3)$ & & $41(30.4)$ & \\
\hline & $16-19$ & $93(26.7)$ & $21(22.6)$ & & $15(16.1)$ & \\
\hline Median age (IQR) & $14(\mathrm{IQR}=12,16)$ & & & & & \\
\hline \multirow[t]{3}{*}{ Age difference from elder sibling } & I am the $1^{\text {st }}$ child for my mother & $77(22.1)$ & $17(22.1)$ & 0.401 & $16(20.8)$ & 0.478 \\
\hline & $<=2$ years & $94(27.0)$ & $28(29.8)$ & & $26(27.7$ & \\
\hline & $>2$ years & $177(50.9)$ & $54(30.5)$ & & $49(27.7)$ & \\
\hline \multirow[t]{3}{*}{ Age difference from younger sibling } & I am the last child for my mother & $55(15.8)$ & $11(20.0)$ & 0.256 & $16(29.1)$ & 0.383 \\
\hline & $<=2$ years & $92(26.4)$ & $30(32.6)$ & & $28(30.4)$ & \\
\hline & $>2$ years & $201(57.8)$ & $58(28.9)$ & & $47(23.4)$ & \\
\hline \multirow[t]{2}{*}{ Usual place of Residence } & Urban & $217(62.4)$ & $51(23.5)$ & 0.008 & $64(29.5)$ & 0.068 \\
\hline & Rural & $131(37.6)$ & $48(36.4)$ & & $27(20.6)$ & \\
\hline \multirow[t]{2}{*}{ Religion } & Orthodox & $323(92.8)$ & $96(27.7)$ & $0.067^{* *}$ & $82(25.4)$ & 0.245 \\
\hline & Muslim & $25(7.2)$ & $3(12.0)$ & & $9(36.0)$ & \\
\hline \multirow[t]{2}{*}{ Education of father } & Illiterate & $127(36.5)$ & $43(33.9)$ & 0.090 & $28(22.1)$ & 0.187 \\
\hline & Literate & $221(63.5)$ & $56(25.3)$ & & $63(28.5)$ & \\
\hline \multirow[t]{2}{*}{ Education of Mother } & Illiterate & $156(44.8)$ & $44(28.2)$ & 0.928 & $33(21.2)$ & 0.056 \\
\hline & Literate & $192(55.2)$ & $55(28.7)$ & & $58(30.2)$ & \\
\hline \multirow[t]{3}{*}{ Occupation of father } & Employed & $150(43.1)$ & $28(18.7)$ & 0.002 & $40(26.7)$ & 0.069 \\
\hline & Farmer & $131(37.6)$ & $48(36.6)$ & & $27(20.6)$ & \\
\hline & Other & $67(19.3)$ & $23(34.3)$ & & $24(35.8)$ & \\
\hline \multirow[t]{2}{*}{ Family size } & $<=4$ members & $98(28.2)$ & $18(18.4)$ & 0.009 & $24(24.5)$ & 0.645 \\
\hline & $>4$ members & $249(71.8)$ & $81(32.5)$ & & $67(26.9)$ & \\
\hline
\end{tabular}

${ }^{*} P$-value was determined using chi-square test except for $* * ; *$ Fisher's exact test

Age was associated with stunting $(p=0.002)$ and thinness $(p=0.036)$. A higher percentage in rural area were stunted $(p=0.008)$ compared to those living in an urban area. Participants whose fathers were farmers had a higher prevalence of stunting than those with other occupations $(p=0.002)$. Larger families were associated with greater prevalence stunting in adolescents $(p=0.009)$. Stunting was found to be higher among families whose members were $>4(p=0.009)($ Table 1$)$.

\section{Eating behavior and hygienic practices in relation to nutrition status}

The majority, (56.3\%) of adolescents consumed "Teff" with "Wot" as a daily staple in the diet and the frequency of consumption most commonly three or more times per day (83.6 \%). Vegetables (91.4\%) and fruits $(89.1 \%)$ were also consumed at least once daily. Three-quarters $(75.5 \%)$ of adolescents ate meat at least once per week. The majority of the adolescents reported that they used piped water and had a functional latrine at their home (Table 2).

\section{Anthropometric measurements}

The mean \pm SD overall height of the participants was $147.6 \pm 11.2 \mathrm{~cm}(95 \% \mathrm{CI}: 146.5,148.8)$ and weight was $37.2 \pm 9.5 \mathrm{~kg}$ (95\% CI: 36.2, 38.2). The mean heights of boys and girls were $147.6 \pm 13.40 \mathrm{~cm}(95 \%$ CI: 145.5 , $149.8)$ and $147.7 \pm 9.10 \mathrm{~cm}(95 \% \mathrm{CI}: 146.4,148.9)$ respectively with no statistical difference between the two groups $(p=0.967)$. Similarly, the mean weights of boy and girl adolescents were $35.9 \pm 9.72 \mathrm{Kg}(95 \% \mathrm{CI}: 34.4,37.5)$ and $38.3 \pm 9.22 \mathrm{Kg}$ (95\% CI: 37.0, 39.6) respectively with statistical difference between the two groups $(P=0.023)$ (data not shown).

The mean height of boy and girl adolescents in relation to age is shown in Fig. 2. Boys were taller at 10 years of age while between the ages of 11 and 13 years, boys were shorter. At the age of 14 years, girls were shorter than boys. 
Table 2 Sanitation practices and eating behavior of adolescents categorized by nutrition status (i.e. stunted and thin), northern Ethiopia, 2014

\begin{tabular}{|c|c|c|c|c|c|c|}
\hline \multirow[t]{2}{*}{ Variables } & \multirow[t]{2}{*}{ Category } & \multirow[t]{2}{*}{ n (\%) } & Stunted & \multirow[t]{2}{*}{$P$-value ${ }^{*}$} & Thin & \multirow[t]{2}{*}{$P$-value* } \\
\hline & & & $n(\%)$ & & $n(\%)$ & \\
\hline \multirow[t]{3}{*}{ Kind of food always eaten at home } & "Teff"with "Wot" & $196(56.3)$ & $46(23.5)$ & 0.051 & $53(27.0)$ & 0.888 \\
\hline & Wheat & $122(35.1)$ & $41(33.6)$ & & $31(25.4)$ & \\
\hline & Others & $30(8.6)$ & $12(40.0)$ & & $7(23.3)$ & \\
\hline \multirow[t]{2}{*}{ Number of feedings per day } & $1-2$ times & $57(16.4)$ & $16(28.1)$ & 0.945 & $15(26.3)$ & 0.975 \\
\hline & $>=3$ times & $191(83.6)$ & $83(28.5)$ & & $76(26.1)$ & \\
\hline \multirow[t]{2}{*}{ Eat vegetable at least once per day } & Yes & $317(91.4)$ & $88(27.8)$ & 0.302 & $84(26.5)$ & 0.706 \\
\hline & No & $30(8.7)$ & $11(36.7)$ & & $7(23.3)$ & \\
\hline \multirow[t]{2}{*}{ Eat fruits at least once per day } & Yes & $309(89.1)$ & $85(27.5)$ & 0.229 & $81(26.2)$ & 0.989 \\
\hline & No & $38(11.0)$ & $14(36.8)$ & & $10(26.3)$ & \\
\hline \multirow[t]{2}{*}{ Eat meat at least once per week } & Yes & $262(75.5)$ & $70(26.7)$ & 0.189 & $63(24.0)$ & 0.105 \\
\hline & No & $85(24.5)$ & $29(34.1)$ & & $28(33.0)$ & \\
\hline \multirow[t]{2}{*}{ Source of water } & Pipe water & 309 (88.8) & $84(27.2)$ & 0.141 & $81(26.2)$ & 0.939 \\
\hline & Other (well, river....) & $29(11.2)$ & $15(38.5)$ & & $10(25.6)$ & \\
\hline \multirow[t]{2}{*}{ Presence of functional latrine at home } & Yes & $310(89.1)$ & $90(29.0)$ & 0.490 & $79(25.5)$ & 0.420 \\
\hline & No & $38(10.9)$ & $9(23.7)$ & & $12(31.6)$ & \\
\hline
\end{tabular}

*P-value was determined using chi-square test

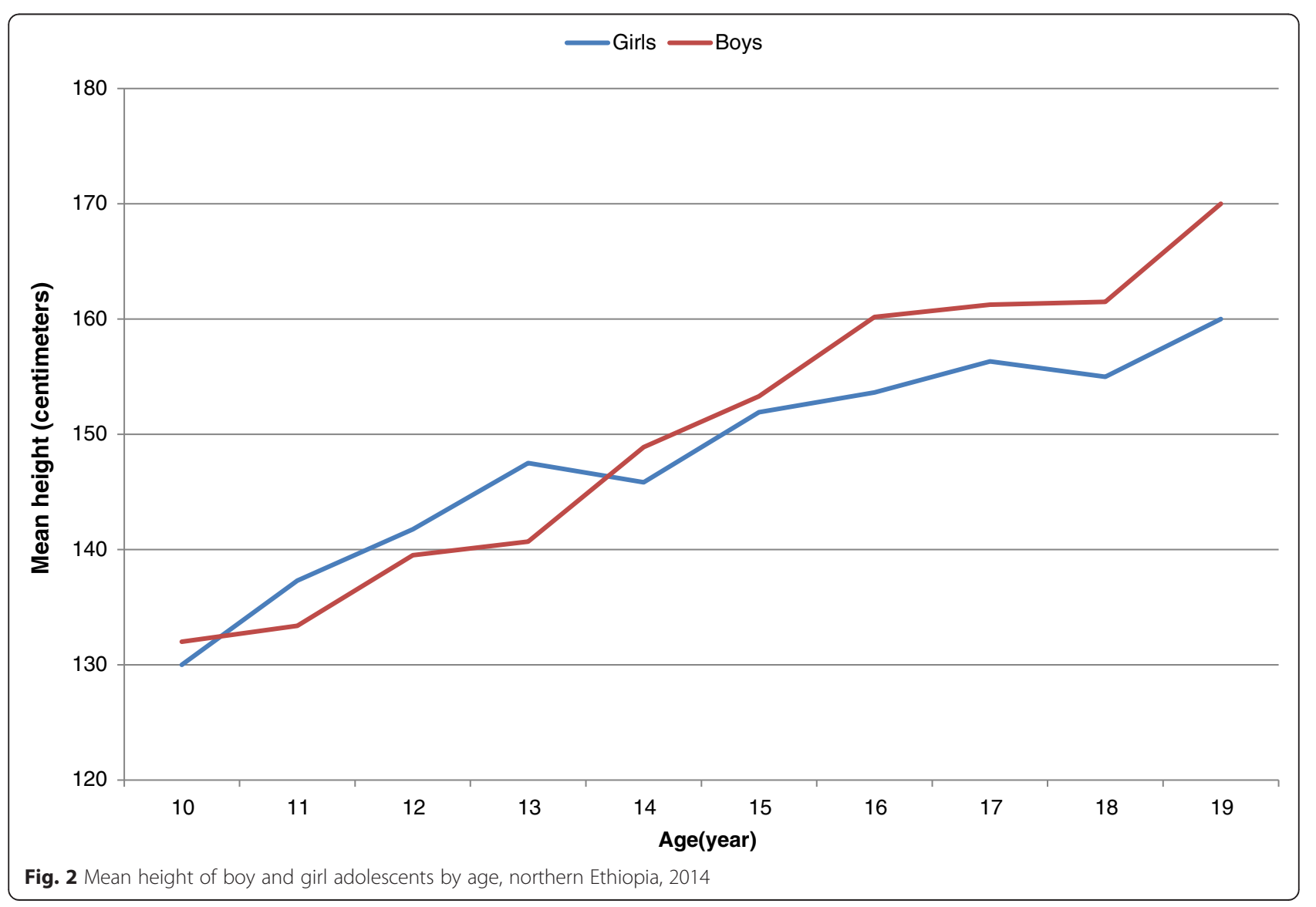


The mean Z-scores of height-for-age and BMI-for-age of all adolescents were -1.49 (95 \% CI:-1.60, -1.39) and -1.29 (95 \% CI:-1.41,-1.18), respectively. The mean Z-scores of height-for-age among boys and girls were -1.68 (95 \% CI: $-1.85,-1.50)$ and-1.34 (-1.48,-1.20) respectively, which are significantly different $(p=0.0028)$. Similarly, the mean Z-scores of BMI-for-age among boys and girls were -1.59 (95 \% CI:-1.75, -1.43 ) and -1.06 (95\% CI: $-1.22,-0.89)$, respectively $(p<0.0001)$. Generally, Z-scores of BMI-for-age and height-for-age for all adolescents and by sex were found to be below the 2006 WHO standards and there were almost no obese cases (Fig. 3).

\section{Prevalence of stunting and thinness}

The prevalence of stunting and thinness among adolescents was $28.5 \%$ (95\% CI: $23.9 \%, 33.4 \%$ ) and $26.1 \%$ (95\% CI: $21.7 \%, 31.0 \%$ ), respectively. The prevalence of severe stunting $(\mathrm{HAZ}<-3 \mathrm{SD})$ and thinness $(\mathrm{BAZ}<-3 \mathrm{SD})$ was $8.1 \%$ and $7.1 \%$, respectively. The trend of stunting $(p=0.711)$ and thinness $(p=0.229)$ across age was not significant (data not shown).

\section{Factors associated with stunting and thinness}

In bivariable logistic regression, sex, age, residence, family size, education of father, type of food usually eaten were found to be significantly associated with stunting. However, in multivariable analysis only sex, age, residence and fathers' occupation were significantly associated with stunting.
Boy adolescents had 2.53 times higher odds of stunting $(\mathrm{AOR}=2.53$; 95 \% CI: 1.52, 4.21) compared to girls. Adolescents age 13-15 years had 2.23 times higher odds of being stunted $(\mathrm{AOR}=2.23 ; 95 \% \mathrm{CI}: 1.22,4.08)$ compared to those aged 10 to 12 , Rural residents had 2.15 times higher odds of being stunted $(\mathrm{AOR}=2.15 ; 95 \% \mathrm{CI}$ : $1.20,3.86)$ than their counterparts. Similarly, a marginal association of the occupation of the father and stunting was detected as adolescents whose fathers' occupation was farmers had 2 times higher odds of being stunted $(\mathrm{AOR}=2.00 ; 95 \% \mathrm{CI}: 1.00,4.00)$ compared to adolescents whose fathers were employed (Table 3).

In multivariable analysis, after adjusting for residence, family size, father's education and type of food usually consumed and sex and age, only sex and age were found to be significantly associated with thinness. Boys had almost 2 times higher odds of being thin $(\mathrm{AOR}=1.97$; 95 \% CI: 1.19, 3.25) compared to girls. Compared to those 10 to 12 years of age, adolescents aged 16 to 19 years were $53 \%$ less likely to be thin $(\mathrm{AOR}=0.47 ; 95 \% \mathrm{CI}: 0.23$, 0.95) (Table 3).

\section{Discussion}

\section{Prevalence of undernutrition}

The present study shows that the extent of undernutrition among adolescents in northern Ethiopia is high. The prevalence of stunting in adolescents was $28.5 \%$ with a significant difference between boys and girls (37.7\% and $21.2 \%$, respectively). Previous studies in adolescent Ethiopians reported much lower levels of stunting. These include studies in the Jimma zone (16\%) [35] and Addis
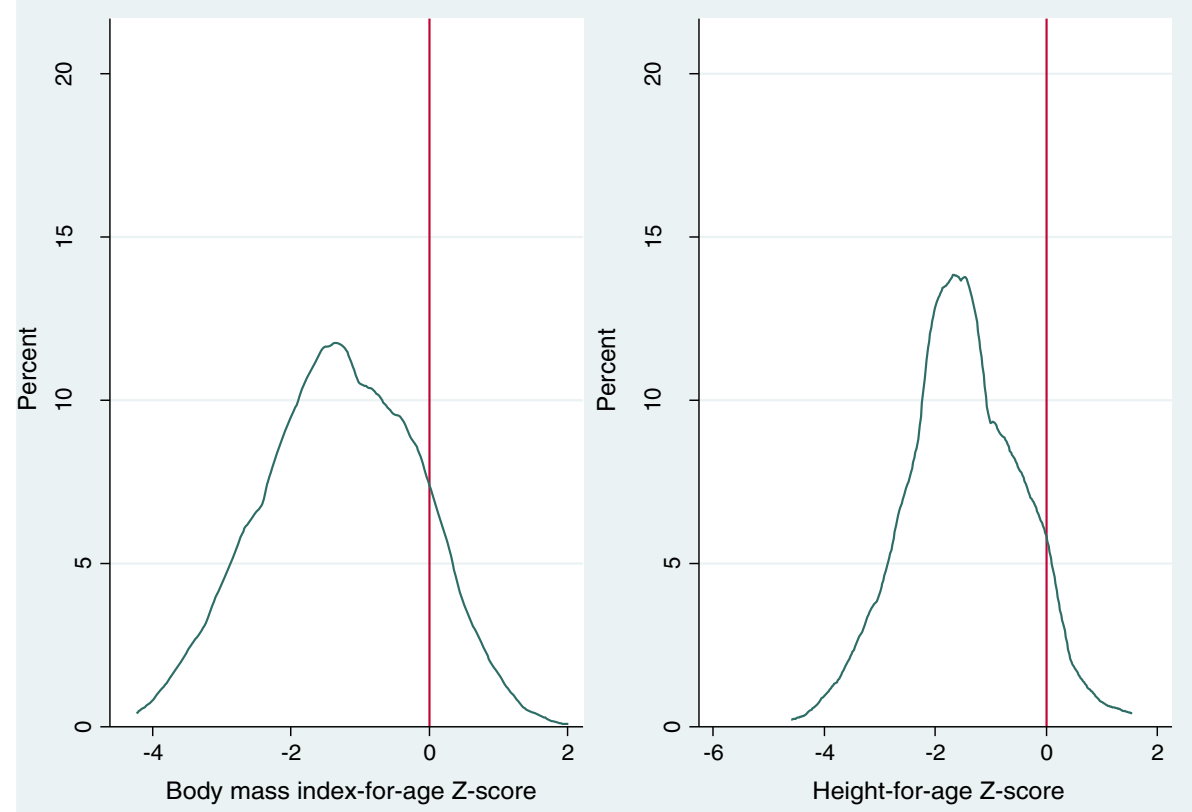

Fig. 3 Kernel density plots of Body-mass-index-for-age and Height-for-age Z-scores for all adolescents, northern Ethiopia, 2014 
Table 3 Factors associated with stunting and thinness among adolescents in northern Ethiopia, 2014

\begin{tabular}{|c|c|c|c|c|c|c|c|}
\hline \multirow[b]{2}{*}{ Variable } & \multirow[b]{2}{*}{ Category } & \multicolumn{3}{|l|}{ Stunting } & \multicolumn{3}{|l|}{ Thinness } \\
\hline & & COR $(95 \% \mathrm{Cl})$ & AOR $(95 \% \mathrm{Cl})$ & $P$-value* & COR $(95 \% \mathrm{Cl})$ & AOR $(95 \% \mathrm{Cl})$ & $P$-value* \\
\hline \multirow[t]{2}{*}{ Sex } & Boy & $2.25(1.40,3.62)$ & $2.53(1.52,4.21)$ & $<0.001$ & $1.79(1.11,2.91)$ & $1.97(1.19,3.25)$ & 0.008 \\
\hline & Girl & 1.00 & 1.00 & & 1.00 & 1.00 & \\
\hline \multirow[t]{3}{*}{ Age } & $10-12$ years & 1.00 & 1.00 & & 1.00 & 1.00 & \\
\hline & $13-15$ years & $2.46(1.40,4.30)$ & $2.23(1.22,4.08)$ & 0.009 & $1.06(0.62,1.81)$ & $1.11(0.63,1.97)$ & 0.712 \\
\hline & $16-19$ years & $1.11(0.58,2.14)$ & $0.83(0.41,1.67)$ & 0.608 & $0.47(0.24,0.92)$ & $0.47(0.23,0.95)$ & 0.035 \\
\hline \multirow[t]{2}{*}{ Residence } & Urban & 1.00 & 1.00 & & 1.00 & 1.00 & \\
\hline & Rural & $1.87(1.16,3.01)$ & $2.15(1.20,3.86)$ & 0.01 & $0.62(0.37,1.04)$ & $0.73(0.40,1.31)$ & 0.286 \\
\hline \multirow[t]{2}{*}{ Family size } & $<=4$ members & 1.00 & 1.00 & & 1.00 & 1.00 & \\
\hline & $>4$ members & $2.14(1.20,3.81)$ & $1.75(0.95,3.21)$ & 0.071 & $1.14(0.66,1.95)$ & $1.15(0.65,2.01)$ & 0.639 \\
\hline \multirow[t]{3}{*}{ Occupation of father } & Employed & 1.00 & 1.00 & & 1.00 & 1.00 & \\
\hline & Farmer & $2.50(1.45,4.30)$ & $1.34(0.99,2.34)$ & 0.234 & $0.71(0.41,1.25)$ & Omitted & \\
\hline & Other & $2.26(1.18,4.33)$ & $2.00(1.00,4.00)$ & 0.05 & $1.54(0.83,2.84)$ & $1.53(0.80,2.91)$ & 0.196 \\
\hline \multirow[t]{3}{*}{ Type of food usually eaten (staple) } & "Teff" with "Wot" & 1.00 & 1.00 & & 1.00 & 1.00 & \\
\hline & Wheat & $1.67(1.01,2.76)$ & $1.34(0.77,2.31)$ & 0.297 & $0.92(0.55,1.54)$ & $1.00(0.58,1.73)$ & 1.000 \\
\hline & Other & $2.17(0.98,4.85)$ & $1.66(0.70,3.95)$ & 0.249 & $0.82(0.33,2.03)$ & $0.85(0.33,2.19)$ & \\
\hline
\end{tabular}

COR-Crude Odds Ratio; AOR-Adjusted Odds Ratio; Cl-Confidence Interval; *Z-test

Ababa (7.2 \%) [14]. Nonetheless, in northern Ethiopia, the prevalence of childhood chronic malnutrition is very high [10] which may have impact on level of adolescent stunting. A number of studies in other African countries including Burkina Faso (8.8 \% [38], $12 \%$ [39]) and Chad $(18.7 \%)$ [40] have reported a lower prevalence of stunting. However, a high prevalence of stunting in adolescent girls has been reported in Bangladesh (32\%) [41], northern Ethiopia (26.5 \%) [12] and Seychelles (23 \%) [42]. In contrast to these countries, In China, a study reported that the prevalence of stunting is much lower to the level that it is no longer a nutritional problem of public health importance [43].

Stunting is an indicator of chronic malnutrition, and at school age, it may reflect malnutrition during the first years of life [9]. Adult short stature results from nutritional deficit at the different phases of growth rather than just in a single phase [44]. Childhood stunting is highly prevalent in Ethiopia [10, 45, 46] and the last chance for curbing the consequences of malnutrition on height is the adolescence period. There is a potential that children who suffered childhood stunting could achieve catch-up growth during adolescence $[47,48]$ although it is usually incomplete [48].

In the current study, the prevalence of thinness was $26.1 \%$. A similar level of thinness was found in Seychelles $(27.7 \%)$ [42]. Another study in Ethiopia, in the Jimma zone, has reported a much higher level $(80.8 \%)$ of thinness prevalence among adolescents [35]. However, other studies in Ethiopia (6.2 \%) [14] and Burkina Faso (13.7 \% [38], $8.0 \%$ [39]) have reported much lower prevalence. In our study, the prevalence of thinness among boys was significantly higher than girls $(32.4 \%$ and $21.6 \%$, respectively). Similarly, in Addis Ababa, the prevalence of thinness among boys was significantly higher than girls (9.8 \% and $2.6 \% ; p<0.01$, respectively) [14]. The prevalence of thinness among girls in our study was lower than studies in Northern Ethiopia (58.3 \%) [12] and Bangladesh (26\%) [41]. On the other hand, our study found higher level of thinness among girls compared to studies in Seychelles (14\%) [42], Iran (10.1 \%) [49], Turkey (11.1 \%) [50], Qatar (5.8 \%) [51] and China (5.2 \%) [43].

In the current study, the mean heights of boy and girl adolescents were 147.6 and $147.7 \mathrm{~cm}$, which were not significantly different $(p=0.967)$. A mean height $(147 \mathrm{~cm})$ among girl adolescents has previously been reported in northern Ethiopia [12]. In this study, the mean weights of boy and girl adolescents were $35.9 \mathrm{~kg}$ and $38.3 \mathrm{~kg}$ which were significantly different. A mean weight of $34.6 \mathrm{~kg}$ of female adolescents was previously reported in northern Ethiopia [12] but in contrast to our study, a study conducted in Addis Ababa found boys to be taller and heavier by $10 \mathrm{~cm}$ and $4 \mathrm{kgs}$, respectively [14]. Again, this may be due to the socio-economic environment, and differences between rural and urban settings in Ethiopia.

In the current study, the mean Z-scores of heightfor-age and BMI-for-age of all adolescents were -1.49 and -1.29 , respectively. In addition, there were no obese cases in the study. In Addis Ababa, Z-scores of height-forage and BMI-for-age of the adolescents were, -0.72 and -0.48 , respectively [14]. In our study, the mean Zscores of height-for-age among boys and girls were -1.68 and -1.34 respectively which are significantly different 
$(p=0.0028)$. In another study in northern Ethiopia, a mean Z-score of height-for-age among girls was reported to be -1.5 [12] which is similar to what our study found. In our study, mean Z-scores of BMI-for-age among boys and girls were -1.59 and $-1.06(p<0.0001)$, respectively. Consistent with our results, a study reported that mean Z-score of BMI-for-age was significantly higher in girls than boys [14]. Overall, our anthropometric data indicated adolescents living in a town which has both rural and urban residents had poorer nutrition status than those that live in the larger capital city of Addis Ababa. Nutritional Policies and programs against adolescent undernutrition should give focus and priority for rural areas where the problem is prevalent. These interventions are also equally important for small towns and peri-urban areas.

Globally, we found that Z-scores of height-for-age and BMI-for-age for all adolescents and by sex were found to be below the 2006 WHO standards. Other studies in Ethiopia have reported similar findings $[12,14]$. The reason for scoring lower means of BAZ and HAZ compared to the WHO growth standard are not surprising as Ethiopia is considered a developing and/or emerging country where poor dieting habits and insufficient food intake remains a concern.

\section{Factors associated with undernutrition}

In this study, adolescent boys had 2.5 times higher odds of stunting compared to girls. This finding is consistent with studies in south-west Ethiopia and Romania $[26,52]$. However, opposite finding has been reported in Extremadura (Spain) [53]. Compared to those 10 to 12 years of age, adolescents $13-15$ years of age had 2.2 times higher odds of being stunted. This finding is consistent with studies in Ethiopia, Burkina Faso and Bangladesh $[12,38,41,54]$ which demonstrated varying prevalence of stunting among different age groups. Rural residents had 2.2 times higher odds of being stunted than their urban counterparts. Similar to our result, studies in Ethiopia and western Africa [27, 35, 38, 55-58] have reported the same findings.

Boys had almost 2 times higher odds of being thin compared to girls which is similar with findings in Ethiopia and Romania [12, 35, 52]. In the current study, adolescents aged 16 to 19 years were $53 \%$ less likely to be thin compared to those aged 10 to 12 years. Association between age and thinness were reported in studies conducted in Ethiopia [12] and Bangladesh [41]. In Ethiopia, national nutritional programs and interventions had special interest and focus on adolescent girls [59, 60]. However, the current study shows that, compared to girls, boy adolescents are significantly being affected by undernutrition. Therefore, nutritional programs and interventions should also give at least equal attention to boys.
Box 1 Key intervention recommendations

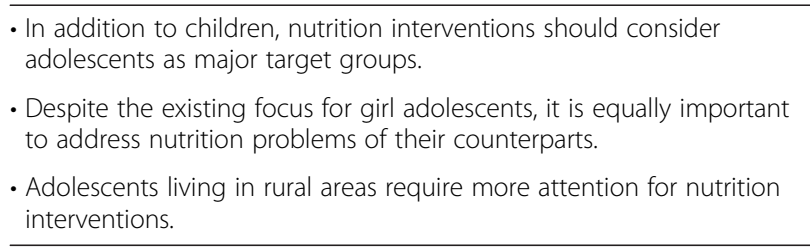

\section{Limitations}

We acknowledge some limitations in this study. Some variables such as the systematic measurement of nutritional knowledge, social and economic status, food security and dietary diversity score were not included. Furthermore, errors during anthropometric measurements are also possible and could lead to measurement bias. However, the data collectors were trained in anthropometric measurement procedures and they were also supervised during data collection. The study also did not collect information related to pubertal landmarks. Studies have shown that chronic under-nutrition can delay sexual maturity and the adolescent growth spurt. As a result, adjustments were not made for differences of ages of sexual maturation, which might confound comparisons between the survey and reference population $[61,62]$.

\section{Conclusions}

Undernutrition is widely prevalent among adolescents in northern Ethiopia. Height-for-age and BMI-for-age scores of all adolescents were found to be below the $2006 \mathrm{WHO}$ standards. Age and residency were found to be important factors associated with stunting. Age was also an important factor associated with thinness. Importantly, unlike previous studies in Ethiopia [12, 34], we found that boys were affected more by undernutrition (both by stunting and thinness) compared to girls. Programs to support nutrition interventions for adolescents could provide an opportunity for healthy transition from childhood to adulthood and could be an important step in breaking the intergenerational cycle of malnutrition. Recognizing the intergenerational effect of malnutrition and high prevalence of adolescent undernutrition, there is a clear need to give due attention to adolescent nutrition. In Ethiopia, strategies in addressing the undernutrition among adolescents (focusing on both boys and girls) are needed in addition to the existing efforts to combat child undernutrition. Further studies with more robust methods are required to explore dietary pattern and nutrient intake and their association with nutritional status of adolescents.

\section{Competing interests}

The authors declare that they have no competing interests.

\section{Authors' contributions}

YAM has designed the study and involved in data collection, supervision and data processing. YAM has cleaned and analyzed the data; as well as interpreted the results and drafted the manuscript. GAZ and ZS participated 
in analyzing and interpreting the data. GAZ, TKG, RJA and ZS have critically reviewed the manuscript. All authors read and approved the final manuscript.

\section{Author's information}

Tiffany K. Gill is currently a National Health and Medical Research Council Early Career fellow (Australian Public Health, ID 1013552).

\section{Acknowledgments}

The study was financially supported by Mekelle University. The authors also express their gratitude to the Tigray Regional Health and Education Bureau, the study participants, data collectors and supervisors for their involvement in the study.

Contents of this publication are solely the responsibility of the authors and do not necessarily represent the official views of the funding organization.

\section{Author details}

${ }^{1}$ School of Public Health, College of Health Sciences, Mekelle University, Mekelle, Ethiopia. ${ }^{2}$ College of Pharmacy and Nutrition, University of Saskatchewan, Saskatoon, Canada. ${ }^{3}$ School of Medicine, The University of Adelaide, Adelaide, South Australia, Australia.

\section{Received: 30 December 2014 Accepted: 3 September 2015}

\section{Published online: 28 October 2015}

\section{References}

1. UNDO/UNFPANHO/World Bank. Special program of Research, Development and Research Training in Human Reproductive Health (HRP), Progress in Reproductive Health Research. WHO production services, Geneva, Switzerland. ISBN 924159191 9; p144; 2003.

2. Ghai OP, Gupta P, Paul VK. Ghai Essential Pediatrics, Adolescent Health and Development. Pediatrics. 2006;6:66.

3. UNICEF: progress for children: a report card on adolescents: UNICEF publications, New York, USA; Number 10, April 2012.

4. Campagna VN, Souza ASL. Corpoeimagem corporal no início da adolescênciafeminina. Bol Psic. 2006;56(124):9-35.

5. Nutrition for the school-aged child. UNL/Cooperative Extension Service. NebGuide Series No.G92-1086-A 2002, 1.

6. WHO. The Management of Nutrition in Major Emergencies. 2nd ed. Geneva: World Health Organization; 2000. p. 236.

7. Shahid A, Siddiqui FR, Bhatti MA, Ahmed M, Khan MW. Assessment of Nutritional Status of Adolescent College Girls at Rawalpindi. Department of Islamic International Medical College, Rawalpindi, Pakistan: HOD Community Medicine; 2010.

8. Ng M, Fleming T, Robinson M, Thomson B, Graetz N, Margono C, et al. Global, regional, and national prevalence of overweight and obesity in children and adults during 1980 - 2013: a systematic analysis for the Global Burden of Disease Study 2013. Lancet. 2014;384:766-81. doi:10.1016/S01406736(14)60460-8.

9. Muller $\mathrm{O}$, Krawinkel M. Malnutrition and health in developing countries. CMAJ. 2005;173(3):279-86.

10. Central Statistical Agency [Ethiopia]. Ethiopia Mini Demographic and Health Survey, Addis Ababa, Ethiopia. 2014.

11. Ethiopian Health and Nutrition Research Institute: Nutrition baseline survey report for the national nutrition program of Ethiopia, Ethiopian Health and Nutrition Research Institute, Addis Ababa, Ethiopia, 2009/2010.

12. Mulugeta A, Hagos F, Stoecker B, Kruseman G, Linderhof V, Zenebe A, et al. Nutritional status of adolescent girls from rural communities of Tigray, Northern Ethiopia. Ethiop J Health Dev. 2009;23(1):5-11.

13. Prentice AM. The emerging epidemic of obesity in developing countries. Int J Epidemiol. 2006;35(1):93-9.

14. Gebreyohannes Y, Shiferaw S, Demtsu B, Bugssa G. Nutritional Status of Adolescents in Selected Government and Private Secondary Schools of Addis Ababa, Ethiopia. Int J Nutr Food Sci. 2014;3(6):504-14. doi:10.11648/ j.ijnfs.20140306.1.

15. Rogol AD, Roemmich JN, Clark PA. Growth at Puberty. J Adolesc Health. 2002;31:192-200

16. Mustanski BS, Viken RJ, Kaprio J, Pulkkinen L, Rose RJ. Genetic and environmental influences on pubertal development: longitudinal data from Finnish twins at ages 11 and 14. Dev Psychol. 2004;40(6):1188-98.
17. Berkey CS, Colditz GA, Rockett HR, Frazier AL, Willett WC. Dairy consumption and female height growth: prospective cohort study. Cancer Epidemiol Biomarkers Prev. 2009;18(6):1881-7.

18. Biro FM, Lucky AW, Simbartl LA, Barton BA, Daniels SR, Striegel-Moore R, et al. Pubertal maturation in girls and the relationship to anthropometric changes: pathways through puberty. J Pediatr. 2003;142(6):643-6.

19. Cheng G, Gerlach S, Libuda L, Kranz S, Günther ALB, Karaolis-Danckert N, et al. Diet quality in childhood is prospectively associated with the timing of puberty but not with body composition at puberty onset. J Nutr. 2010;140(1):95-102.

20. Rogol AD, Clark PA, Roemmich JN. Growth and pubertal development in children and adolescents: effects of diet and physical activity. Am J Clin Nutr. 2000;72(2 Suppl):521S-8.

21. Hadley C, Lindstrom D, Tessema F, Belachew T. Gender bias in food insecurity experiences of adolescents in Jimma zone. Soc Sci Med. 2008;66(2):427-38.

22. Belachew T, Hadley C, Lindstrom D, Gebremariam A, Lachat C, Kolsteren P. Food insecurity, school absenteeism and educational attainment of adolescents in Jimma Zone Southwest Ethiopia: a longitudinal study. Nutr J. 2011;10:29.

23. Harrison KA, Fleming AF, Briggs ND, Rossiter CE. Growth during pregnancy in Nigerian primigravidae. Br J Obstet Gynaecol. 1985;92 Suppl 5:32-9.

24. Naeya RL. Teenaged and pre-teenaged pregnancies: consequences of the fetal maternal competition for nutrients. Paediatrics. 1981;67:146-50.

25. Brabin L, Brabin BJ. The cost of successful adolescent growth and development in girls in relation to in relation to iron and vitamin A status. Am J Clin Nutr. 1992;55:955-8.

26. Deshmukh P, Gupta S, Bharambe M, Dongre M, Kaur S, Garg B. Nutritional Status of Adolescents in Rural Wardha Indian. J Pediatrics. 2006;73(2):139-41.

27. Mesert $Y$, Jemal H, Hailu K, Fleming L. Socioeconomic and demographic factors affecting body mass index of adolescents students aged 10-19 in Ambo, Ethiopia. Int J Biol Sci. 2010;6(4):321-6.

28. Carvalho $\mathbb{H}$, Francescantonio $M$, Neutzling $M$, Taddei A. Risk factors for overweight and obesity in adolescents of a Brazilian university: a case-control study. Nutr Hosp. 2009;24:17-24.

29. WHO. Anthroplus for personal computers manual: Software for assessing growth of the world's children and adolescents. Department of Nutrition for Health and Development. Geneva: WHO; 2009. (Available from: http:// www.who.int/growthref/en/) [Accessed on August 25, 2014].

30. Gomes Fda S, Anjos LA, Vasconcellos MT. Influence of different body mass index cut-off values in assessing the nutritional status of adolescents in a household survey. Cad Saude Publica. 2009;25:1850-7.

31. Silva HG, Chiara VL, Barros ME, Rego AL, Ferreira A, Pitasi BA, et al. Diagnosing the nutritional status of schoolchildren: a comparison between Brazilian and international criteria. J Pediatr (Rio J). 2008;84:550-5.

32. BayaBotti A, Perez-Cueto FJ, Vasquez Monllor PA, Kolsteren PW. International BMl-for-age references underestimate thinness and overestimate overweight and obesity in Bolivian adolescents. Nutr Hosp. 2010;25:428-36.

33. Khasnutdinova SL, Grjibovski AM. Prevalence of stunting, underweight, overweight and obesity in adolescents in Velsk district, north-west Russia: a cross-sectional study using both international and Russian growth references. Public Health. 2010;124:392-7.

34. Belachew T, Lindstrom D, Hadley C, Gebremariam A, Kasahun W, Kolsteren P. Food insecurity and linear growth of adolescents in Jimma Zone, Southwest Ethiopia. Nutr J. 2013;12:55.

35. Assefa H, Belachew T, Negash L. Socioeconomic Factors Associated with Underweight and Stunting among Adolescents of Jimma Zone, South West Ethiopia: A Cross-Sectional Study. ISRN Public Health 2013: 7. Hindawi Publishing Corporation. http://dx.doi.org/10.1155/2013/238546.

36. de Onis M, Onyango AW, Borghi E, Siyam A, Nishida C, Siekmann J. Development of a WHO growth reference for school-aged children and adolescents. Bull World Health Organ. 2007;85:660-7.

37. Hosmer DW, Lemeshow S. Applied Logistic Regression. 2nd ed. New York: J Wiley and Sons; 2000.

38. Daboné C, Delisle HF, Receveur O. Poor nutritional status of schoolchildren in urban and peri-urban areas of Ouagadougou (Burkina Faso). Nutr J. 2011;10:34.

39. MEBA: Enquête de base du projet de santé et nutrition scoliare- Rapport présenté par Helen Keller International (HKI). Ministère de l'Enseignement de Base et de l'Alphabétisation-Burkina Faso, 2007, 31.

40. Beasley M, Brooker S, Ndinaromtan M, Madjiouroum EM, Baboguel M, Djenguinabe $E$, et al. First nationwide survey of the health of schoolchildren in Chad. Trop Med Int Health. 2002;7(7):625-30. 
41. Alam N, Roy SK, Ahmed T, Ahmed AMS. Nutritional Status, Dietary Intake, and Relevant Knowledge of Adolescent Girls in Rural Bangladesh. J Health Popul Nutr. 2010;28(1):86-94.

42. Bovet $P$, Kizirian N, Madeleine G, Blössner M, Chiolero A. Prevalence of thinness in children and adolescents in the Seychelles: comparison of two international growth references. Nutr J. 2011;10:65.

43. Shi Z, Lien N, Kumar BN, Dalen I, Holmboe-Ottesen G. The sociodemographic correlates of nutritional status of school adolescents in Jiangsu Province, China. J Adolesc Health. 2005;37:313-22. doi:10.1016/j.jadohealth.2004.10.013.

44. Luo ZC, Karlberg J. Critical Growth Phases for Adult Shortness. Am J Epidemiol. 2000;152:125-31.

45. Central Statistical Agency [Ethiopia] and ICF International. Ethiopia Demographic and Health Survey 2011. Addis Ababa, Ethiopia and Calverton, Maryland, USA: Central Statistical Agency and ICF International; 2012

46. Central Statistical Agency [Ethiopia] and ICF International. Ethiopia Demographic and Health Survey 2005. Addis Ababa, Ethiopia and Calverton, Maryland, USA: Central Statistical Agency and ICF International; 2006.

47. Coly AN, Milet J, Diallo A, Ndiaye T, Bénéfice E, Simondon F, et al. Preschool stunting, adolescent migration, catch-up growth, and adult height in young Senegalese men and women of rural origin. J Nutr. 2006;136(9):2412-20.

48. Golden MHN. Is complete catch-up possible for stunted malnourished children? Eur J Clin Nutr. 1994;48(Supplement):S58-S71.1.

49. Talaie-Zanjani A, Faraji F, Rafie M, Mohammadbeigi A. A Comparative Study of Nutritional Status and Foodstuffs in Adolescent Girls in Iran. Ann Med Health Sci Res. 2014;4(1):38-43. doi:10.4103/2141-9248.126606.

50. Oner N, Vatansever U, Sari A, Ekuklu E, Güzel A, Karasalihoğlu S, et al. Prevalence of underweight, overweight and obesity in Turkish adolescents. Swiss Med Wkly. 2004;134:529-33.

51. Bener A. Prevalence of obesity, overweight, and underweight in Qatari adolescents. Food Nutr Bull. 2006:27:39-45.

52. Elena R, Luminit OC. Adolescent Malnutrition from Anthropological Perspective, "Francisc I. Rainer" Institute of Anthropology. Proc. Rom. Acad., Series B, 2007, 2, p. 155-158. Romanian Academy, 2007.

53. Cabrera JF, Medina EA, Ramos MGC, León AH, Bernabé JAR, Pérez-Nevado F. Evaluación del estadonutricional de estudiantes adolescents de Extremadura basadoenmedidasantropométricas. Nutr Hosp. 2014;29(3):665-73.

54. PCD. The anthropometric status of schoolchildren in five countries in the partnership for child development. Proc Nutr Soc. 1998;57(1):149-58.

55. Oninla SO, Owa JA, Onayade AA, Taiwo O. Comparative study of nutritional status of urban and rural Nigerian school children. J Trop Pediatr. 2007;53(1):39-43.

56. Teller $\mathrm{H}$, Yimar $\mathrm{G}$. Levels and determinants of malnutrition in adolescent and adult women in Southern Ethiopia. Ethio J Health Dev. 2000;14(1):57-66.

57. Woldemariam G, Genebo T. Determinants of Nutritional Status of Women and Children in Ethiopia, Ethiopia. Addis Ababa, Ethiopia; Calverton, Md, USA: Health and Nutrition Research Institute; ORC Macro; 2002.

58. Zerihun T, Larson CP, Hanley JA. Anthropometric status of Oromo women of child bearing age in rural southwestern Ethiopia. Ethio J Health Dev. 1997;11(3):1-7.

59. Federal Minister of Health of Ethiopia (FMoH), National Nutritional Program (NNP) 2008; Addis Ababa, Ethiopia, 2008

60. Federal Minister of Health of Ethiopia $(\mathrm{FMOH})$, National Nutritional Program (NNP) 2013; Addis Ababa, Ethiopia, 2013

61. Woodruff BA, Duffield A. Anthropometric assessment of nutritional status in adolescent population in humanitarian emergencies. Eu J Clin Nutr. 2002;56:1108-18

62. Ahmed F, Zareen M, Khan MR, Banu CP, Haq MN, Jackson AA. Dietary patterns, nutrient intake and growth of adolescent school girls in urban Bangladesh. Pub Health Nutr. 1998;1:83-92.

\section{Submit your next manuscript to BioMed Central and take full advantage of:}

- Convenient online submission

- Thorough peer review

- No space constraints or color figure charges

- Immediate publication on acceptance

- Inclusion in PubMed, CAS, Scopus and Google Scholar

- Research which is freely available for redistribution

Submit your manuscript at www.biomedcentral.com/submit 